\title{
Simulation analysis on the Influence of Physical Exercises on Youths' Physical and Mental Health
}

\author{
Ming Yang \\ Department of Sports, Sichuan University of Arts and Science, Dazhou 635000, Chinia \\ xxzengphysics@163.com
}

Keywords: Physical exercise; Mental health; Physical health; Influence

\begin{abstract}
The importance of physical exercise is investigated by analyzing the effects of exercise on the youth's mental and physical health. We also discuss the effect of physical exercise on youth's body shape, body composition, physical function index, and physical quality index by data analysis. Our result shows that we should pay attention to physical education teaching, improve exercise interest level, and promote more students to participate in physical exercise, so that the youths have healthier body.
\end{abstract}

\section{Introduction}

According to statistics, in 1977-1986, among students who quitted their school in the three Southwestern provinces in China, $42 \%$ of them were due to neurasthenia and schizophrenia, which ranked the $1^{\text {st }}$ among all the diseases ${ }^{[1]}$. At the same time, the latest data show that 13 million of Shanghai's population of up to 75 people with various types of psychological or mental disorders, patients with long-term living, learning and work under the pressure of young people, because the long-time of overload operation and suffering from such diseases, these data reflect that the mental health status of contemporary youth is very serious, and it is worthy of widespread concern in the society. In this paper, we concentrate on investigating the effect of exercise on the health of youth and we hope our result is helpful to improve the health of youth.

\section{Special Function and Roles of Physical Exercises}

\section{Educational Function}

Physical education and mental health education have the same connotation, it is the health education to the human body, the body's physical health is intuitive, and the mental health is the inner abstract, physiological health is the basis of mental health, but the two are also complementary, interdependent and mutually reinforcing. College physical education is not only for students in physical and technical aspects of education, but also in the mental health education, and physical education should be combined with physical education to carry out mental health education. This kind of educational environment has its own special nature, it can fully show the feeling of the educated people, whether it is success or failure, firm or shake, happy or sad, at the same time by the educated themselves can also feel, and teachers can guide and help them in the movement process, lead them to a healthy and positive mental emotional activities.

\section{Function of Regulating Mental Health}

In the face of injustice, frustration or failure, contemporary college students tend to have depression, irritability and other issues. Students want to adjust themselves to the psychological, the emotional outlet, the transfer of the mentality of sports is an effective way, has a good regulation of mental health balance function.

This topic selected 60 college students from different departments of Chongqing Education College to carry out the questionnaire survey[2-5], the problem is that in the face of injustice and frustration will choose what way to adjust the mentality. The answer is the following five, respectively: (1) Sleeping; (2) Watching TV or watching the film for relaxation; (3) Reading or Reading magazines; (4) Sports; (5) The other way. Which accounted for the highest of (4) option, 
reached $45 \%$, and the remaining from high to low in turn for (2) $30 \%,(5)$ accounted for $13 \%$, (1) accounted for $10 \%$, (3) accounted for $2 \%$.

In the last few years, the leisure sports in the whole country will be combined with exercise and recreation, and the mental health of the human body is stressed. Such as golf, tennis, Tai Chi, fishing, etc., which can be adjusted to the mental state and emotional sports events, sports, and the way of sports is easy. After the end of a day of busy work to learn to relax and adjust the mentality, more optimistic and happy face of life.

\section{Promote the Development of Youth'S Physiology and Psychology}

For college students, physical exercise can not only improve their physical quality, but also to a certain extent, to ensure the development of psychological quality, to provide the essential material basis for its physical and psychological development of college students have some help ${ }^{[4-5]}$. The brain is not only the body's organs; it is the material carrier carrying the soul. Each part of the individual is related to the brain, and every movement of the body affects the development of the brain and nervous system. This also means that physical exercise will affect mental health. Specifically, appropriate physical exercise can provide a steady stream of nutrients to the brain. According to the results of the study show that people who often take part in physical exercise in the blood of every cubic millimeter than those who do not often participate in physical exercise more than 100 150 million, corresponding, blood circulation is also not often exercise 2 times or more. And these are due to take part in physical exercise and more blood circulation in the brain to provide adequate nutrition and oxygen at the same time, but also to effectively prevent brain fatigue, therefore, the amount of physical exercise can also enhance human intelligence to a certain extent. The United States has a mental disease scientists have been studying the discovery, because the human brain is really the president of the new cells, and therefore, physical exercise is really to some extent, to some extent, to promote human brain cells. In addition, there are related experiments show that RNA in brain tissues were also increased from ten percent to fifteen percent, and the main function is to promote the pituitary RNA of neurohormone secretion, which is also known as a neurohormone peptide composed of new protein molecules, known as molecular memory. This molecule can effectively promote human brain development. As far as we know, the production and formation of each sport skill has the participation of the cerebral cortex, which is the hand, every sport event will stimulate the brain's cortex[6-7]. Therefore, the correct physical exercise for the promotion of the consideration of skills and their normal and healthy development are not negligible, in addition, physical exercise can effectively improve the performance of the nervous system[7], such as conduction performance and other brain functions, these have provided important material guarantee for the development of psychological.

\section{Improve the Mental Level of Young People}

Usually, the influence of physical exercise on College Students' intellectual development is reflected in three aspects. First of all, in the development and utilization of the brain, sports have an indispensable role and also to a certain extent play a role in enhancing the nervous system; Secondly, physical exercise can not only reduce the stress reaction of human beings, but also can improve the work efficiency of workers; The final physical exercise can effectively relieve the fatigue caused by brain fatigue. That is to say, physical exercise not only makes the internal mechanism of College Students' tension relieved, but also can improve the working ability of the nervous system. As far as we know, the brain cortex is usually in the process of learning in an abnormal state of excitement. However, with the continuous increase in learning time, this excitement will be suppressed, thereby reducing the efficiency of learning[8-9]. In physical exercise, physical activity and mental activity, which makes the central nervous system will also be in a state of excitement, while the study is related to the center of the temporary rest, so that the resulting fatigue can be relieved, thereby further improving the learning efficiency. In addition, physical exercise can improve the physical quality and health level of college students, so that students can take a long learning task, but also to ensure the improvement of learning efficiency[10]. 


\section{Effects of Physical Exercise on Physiological Health of Young Students}

Young students are the national key trained talents, so their physical heath is directly associated with the future development of China as well as the prosperity of the nation. According to the national youth health survey report we can see that in the past five years, the rate of obesity in our country is rapidly rising, with the decline of the physical quality of the students. So at present, college PE teachers need to consider how to improve youth students' physique the most. This study analyzes the influence of physical exercise on College Students' physical health, and provides reference data for physical health.

\section{Methods and Objects of Research}

\section{Object of Study}

Students are chosen from The China Academy of Art, including 104 boys and 120 girls

\section{Research Method}

\section{Contrast Test}

Test Specification

Body weight, height, BMI, body surface area and body volume and other physical forms of the original indicators and derived indicators; Vital capacity and other body functions; The evaluation index of standing long jump, sprint and other physical fitness; To jump, slide down running agility evaluation index variable cross; Body fat percentage, skeletal muscle mass, bone mineral content and other body composition index.

Test Approach

8-9 the most common exercise programmes with moderate intensity are chosen as the practice content. 4 programmes are chosen at random as class exercises and extracurricular exercises, which last for 1 hour respectively. The experiment lasts for one semester and the programme is taken four times a week. Before and after the experiment, the students' physical fitness tests were conducted in accordance with the national standards of the system. The instrument and the index were chosen according to the state regulations. The Korean Inbody 520 instrument is used to measure the body composition.

\section{Mathematical Statistics}

In the computer, the index data information is entered into the computer and the SPSS18.0 software is used to carry out mathematical statistics. The data in this study are measured, compared with the $\mathrm{t}$ test, $\mathrm{P}<0.05$ indicates significant difference, and then the statistical results are analyzed.

\section{Results and Analysis}

\section{Effects of Physical Exercise on the Body Shape Index}

According to table 1 and table 2, we can see that physical exercise has a positive effect on the height and weight of young students, but the difference is not significant, because of this age, although there is still some physical development, but the height and weight of the body has become stable. The BMI index decreases slightly, and the BMI index of the girls increases slightly, but the difference was not significant, and the $18.5 \sim 22.8 \mathrm{~kg} / \mathrm{m} 2$ index is in the range of the standard body shape. Height and weight is derived from the body size and body surface area, which is determined by the basic metabolism, although the body volume and surface area of the experimental subjects have increased, because the body is more stable, so the difference is not significant.

\begin{tabular}{|c|c|c|c|l|c|}
\hline Time & Height $(\mathrm{cm})$ & Weight $(\mathrm{kg})$ & BMI $\left(\mathrm{kg} \cdot \mathrm{m}^{2}\right)$ & $\begin{array}{l}\text { Body } \\
\text { Volume }\left(\mathrm{m}^{3}\right)\end{array}$ & $\begin{array}{l}\text { Body Surface } \\
\text { Area }\left(\mathrm{m}^{2}\right)\end{array}$ \\
\hline $\begin{array}{c}\text { Before } \\
\text { Experiment }\end{array}$ & $172.39 \pm 5.84$ & $63.09 \pm 8.10$ & $21.15 \pm 2.20$ & $0.053 \pm 0.006$ & $1.862 \pm 0.137$ \\
$\begin{array}{c}\text { After } \\
\text { Experiment }\end{array}$ & $173.83 \pm 5.97$ & $63.60 \pm 8.71$ & $20.97 \pm 2.35$ & $0.053 \pm 0.006$ & $1.880 \pm 0.144$ \\
\hline $\mathrm{t}$ value & 1.76 & 0.44 & 0.59 & 0.47 & 0.83 \\
\hline $\mathrm{P}$ & $>0.05$ & $>0.05$ & $>0.05$ & $>0.05$ & $>0.05$ \\
\hline
\end{tabular}

Table 1 Contro Chart of Male Students' Body Shape Before and After Physical Exercise 


\begin{tabular}{|c|l|l|l|l|c|}
\hline Time & Height $(\mathrm{cm})$ & Weight $(\mathrm{kg})$ & $\begin{array}{c}\text { BMI } \\
\left(\mathrm{kg} \cdot \mathrm{m}^{2}\right)\end{array}$ & $\begin{array}{l}\text { Body } \\
\text { Volume }\left(\mathrm{m}^{3}\right)\end{array}$ & $\begin{array}{l}\text { Body } \\
\text { Area }\left(\mathrm{m}^{2}\right)\end{array}$ \\
\hline $\begin{array}{c}\text { Before } \\
\text { Experime } \\
\mathrm{nt}\end{array}$ & $159.23 \pm 5.40$ & $52.4 \pm 6.89$ & $20.77 \pm 2.22$ & $0.047 \pm 0.005$ & $1.634 \pm 0.117$ \\
\hline $\begin{array}{c}\text { After } \\
\text { Experime } \\
\mathrm{nt}\end{array}$ & $160.23 \pm 5.46$ & $54.05 \pm 6.90$ & $21.16 \pm 2.22$ & $0.048 \pm 0.005$ & $1.663 \pm 0.117$ \\
\hline $\mathrm{t}$ value & 1.43 & 1.85 & 1.35 & 1.86 & 1.92 \\
\hline $\mathrm{P}$ & $>0.05$ & $>0.05$ & $>0.05$ & $>0.05$ & $>0.05$ \\
\hline
\end{tabular}

Table 2 Comparison of Body Shape of Female Students Before and After Sports

\section{The Influence of Sports Items on Physical Function Index}

The vital capacity is a kind of index which is reflected by the maximum ventilation quantity of a breath, which is influenced by the factors such as height, chest elasticity and the degree of respiratory muscle development. The air time reflects the static respiratory muscle endurance and movement control force, and the better the effects of physical exercises are, the longer the air time. In Table 3 and 4 we can see that, through the exercise, boys and girls' vital capacity has been significantly improved with significant differences in $\mathrm{P}<0.01$, and the holding time differences between boys are especially, indicating that physical exercises can greatly influence the indexes of college students' two physical functions: vital capacity and holding time.

\begin{tabular}{|l|l|l|}
\hline Time & Vital Capacity $(\mathrm{ml})$ & Holding Time $(\mathrm{s})$ \\
\hline Before Experiment & $4303.71 \pm 594.00$ & $64.42 \pm 15.99$ \\
\hline After Experiment & $4570.16 \pm 723.31$ & $71.68 \pm 13.62$ \\
\hline t value & 2.90 & 3.52 \\
\hline $\mathrm{P}$ & $<0.01$ & $<0.01$ \\
\hline
\end{tabular}

Table 3 Comparison of the Body Function of Male Students Before and After the Experiment

\begin{tabular}{|l|l|l|}
\hline Time & Vital Capacity $(\mathrm{ml})$ & Holding Time $(\mathrm{s})$ \\
\hline Before Experiment & $2865.70 \pm 496.24$ & $56.23 \pm 13.42$ \\
\hline After Experiment & $3177.39 \pm 989.15$ & $58.96 \pm 17.20$ \\
\hline t value & 3.09 & 1.37 \\
\hline $\mathrm{P}$ & $<0.01$ & $>0.05$ \\
\hline
\end{tabular}

Table 4 Comparison of the Body Function of the Female Students Before and After the Experiment

\section{Conclusions and Recommendations}

Through physical exercises, college students' physical fitness and functions have been greatly improved, while the body fat and the percentage of body fat are more obvious, and will not affect the body shape.

While choosing physical exercise programmes, youth students should make the choice according to their interests and hobbies. In future teaching, teachers should further enrich the teaching contents and improve the degree of interest to allow students actively participate in extracurricular physical exercises and improve their physique during the entertainment. 


\section{References}

[1] G.E. Roytberg, I.D. Slastnikova, O.Ju. Dmitrieva. Effects of acute physical exercise of varying intensity on lipid metabolism in middle aged men. Racional'naâ Farmakoterapiâ Kardiologii, 2012,6(4)

[2] L. Dušanka, R. Snežana, M. Ivana. Relations between physical self-concept and physical exercise of primary school pupils. Zbornik Instituta za Pedagoška Istraživanja, 2010, 40(2)

[3] V. W. Hanna, S. Martijn, H. Wim. Design of the Physical exercise during Adjuvant Chemotherapy Effectiveness Study (PACES): A randomized controlled trial to evaluate effectiveness and cost-effectiveness of physical exercise in improving physical fitness and reducing fatigue. BMC Cancer, 2011, 10(1).

[4] J. Caravaca, E. S. Olivas, M. Bataller, et al. Application of machine learning techniques to analyze the effects of physical exercise in ventricular fibrillation. Computers in Biology and Medicine, 2014, 45:1-7.

[5] Y. Wu, Y. S. Ding, H. Xu. AHP-FCE Based Physical Exercise Risk Evaluation Model. Journal of Donghua University (English Version), 2007, 24(5):667-671.

[6] H Littbrand, M Stenvall, E Rosendahl, et al. Applicability and effects of physical exercise on physical and cognitive functions and activities of daily living among people with dementia: a systematic review[J].American Journal of Physical Medicine and Rehabilitation, 2011,90(6):495-518.

[7] B. Sanudo, L. Carrasco, M. D Hoyo. Are Improvements in Physical Fitness after an Exercise Program Related to the Symptomatology in Patients with Fibromyalgia. Journal of Social Sciences, 2013,7(3).

[8] C. Enea, F. Seguin, J. Petitpas-Mulliez, 1H NMR-based metabolomics approach for exploring urinary metabolome modifications after acute and chronic physical exercise. Analytical and bioanalytical chemistry,2010,396(3):1167-1176.

[9] G. Tekin, M. T. Amman, A.Tekin. The effect of recreational physical exercise on depression and assertiveness levels of university students. International Journal of Human Sciences, 2009,6(2).

[10]Y. Su. Fat cell-secreted adiponectin mediates physical exercise-induced hippocampal neurogenesis:an alternative anti-depressive treatment?. Nerve Regeneration Research (English Version), 2015,(1):7-9. 